\title{
AN INSTRUCTIONAL DESIGN MODEL FOR TPACK OBJECT-BASED MATHEMATICS CARD GAMES
}

\author{
Olatoye Mukaila Ayinde ${ }^{1}$ \\ ${ }^{1}$ Ph.D., Lagos State Ministry of Education, Education District III, Falomo, Lagos State, Nigeria.
}

\section{ARTICLE INFO}

Recieved: 12 October 2021 Revised: 31 October 2021 Accepted: 02 November 2021

Keywords:

Game Model, Instructional Object Based Game, Content Selection, Formative Research, Research Paradigm And Learners' Performance.

Corresponding Author: Olatoye Mukaila Ayinde

Email: mukailaolatoye@yahoo.co.uk Copyright (c) 2021, Middle Eastern Journal of Research in Education and Social Sciences.

This work is licensed under the Creative Commons Attribution International License (CC BY 4.0). http://creativecommons.org/licenses/ by/4.0/
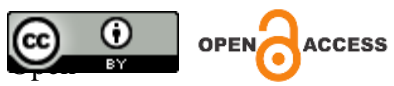

\begin{abstract}
Purpose: This study examined TPACK model as it relates to teacher's knowledge categories such as methods of teaching subject matter (content knowledge) curriculum knowledge, knowledge about technology and pedagogical know-how etc.

Approach/Methodology/Design: Conceptual analysis was discussed to establish content selection, performance procedure and problem-solving while designing an object-based game. Among the templates identified and used for Object-Based Game model are analog game model, managing learning procedure etc. The study adopted formative research in order to elucidate functional concepts and variables within the study.

Findings: Games are repertoire of teaching aids and research paradigm which revolves philosophical learning theories and gaming processes. The quality of game developed depends on the qualifications; i.e. proficiency in mathematical theories and their interrelations to suit instructional concepts of game development and creative thinking abilities, pedagogical skills are required to identify learning pattern. There is a need to incorporate self-motivated experience scenes such as gaming, which characterize play and activity as being the young child's most powerful tool in all areas of learning particularly Mathematics.

Practical Implications: The study presents practical implications for teachers of mathematics. Contextualization helps learners to link new ideas to prior knowledge, and the proposed model in this study could be validated and applied in teaching mathematic concepts.

Originality/value: The study adopted formative research in order to elucidate functional concepts and variables within the study. Technological Pedagogical and Content Knowledge (TPACK) object-based Mathematic card games model is designed as powerful and potential learning tools.
\end{abstract}

\section{INTRODUCTION}

Enhancing teaching and learning outcomes through technology has been a major concern in the educational block. Many researchers identify inherent unfairness in school-based teaching techniques, lack of adequate instructional materials, truancy, and assessment (Asim, 2007), which may result from teachers' incompetency in assessment and learning delivery (Asim, Kalu, Idaka, \& Bassey, 2009). These problems have been blamed in part, on the methods of 
imparting knowledge to educators. The general consensus is that, the mode of instruction has become grossly inadequate to handle the needs of learners. The present delivery system is considered obsolete, inefficient and incapable of achieving pedagogical objectives (Chandra \& Lioyd, 2008).

Inadequacy of instructional materials and lack of effective teaching strategies resulted in the decline in the standard of education and its detrimental effects on the social-economic and technological development of most developing countries in Africa. This has been a major challenge in educational thinking and policy formulations in recent times. Some scholars blame the colonizers of Africa for applying direct transfer of Western curricula, examinations and teaching methods, which fail to address the continental challenges of Africa (Asim et al. 2009). Olatoye (2002) explained that the result of this direct transfer of western curricula, in science and Mathematics decontextualized pedagogical objectives and knowledge being transmitted by poorly trained teachers. As a consequence, the situation in Nigeria is that, academic performance in post-primary education is still deplorably low particularly in Mathematics, both in the certificate and non-certificate examinations (Asimeng-Boahene, 2010).

\section{Statement of Problem}

The scrutiny of how well students are learning depends heavily on the assessment of teaching effectiveness. Teaching effectiveness in this context is the act or skill in the organization of pedagogy, content and knowledge of subject matter that does not devoid adequate instructional technology. Shulman (1986) asserts teaching as pedagogy that involves knowledge of how to take advantage of different teaching approaches that make a learning experience most suitable for the learners. This includes being flexible and adjusting instruction to account for various learning styles, abilities and interests of learners. The variances of pedagogical and technological approaches become a necessity to address the present-day abstract and drill teaching "chalk-talk, talk-talk" that dominated both private and public schools.

There is a need, however, to incorporate self-motivated experience scenes such as gaming, which characterize play and activity as being the young child's most powerful tool in all areas of learning particularly Mathematics. The gaming activities used in the current study integrated content-specific technologies and appropriate pedagogies (e.g., problem-based learning), grounded in Technological, Pedagogical and Content Knowledge (TPACK) framework and designed using gaming as process technology.

\section{LITERATURE REVIEW}

\section{TPACK and Mathematics}

Scholars in the fields of educational technology and teacher education have extended Shulman's opinion about teacher knowledge by including a third component - technological knowledge (Hughes, 2000, 2010; Niess, 2005).Mishra and Kohler (2009) formally introduced the union of these three different types of knowledge as representative of what teachers need to know, coining the combined framework "Technological Pedagogical and Content Knowledge" (TPACK). Essentially, TPACK consists of the negotiation of synergy between three forms of 
knowledge: (1) technological content knowledge, (2) pedagogical content knowledge and (3) technological pedagogical content knowledge (Mishra \& Kohler, 2009).

Cox (2008); defines TPACK and identified its features by attempting to tease out and capture the complexities inherent within the teacher knowledge framework. After considering the plethora of TPACK descriptions, Cox defines TPACK as:

[...] knowledge of the dynamic, transactional negotiation among technology, pedagogy, and content and how that negotiation impacts student learning in a classroom context (p.187).

The essential features are (a) the use of appropriate technology (b) in a particular content area (c) as part of a pedagogical strategy (d) within a given educational context (e) to develop students' knowledge of a particular topic or meet an educational objective or student need. In addition, TPACK offers the fields of Mathematics, technology and teacher education a research framework for guiding pre- and in-service teachers' knowledge assessment and development as well as technology integration in their classrooms (Doering, Veletsianos, \&Scharber, 2007).

It is, therefore, important for instructional media producers to model or design instructional media using templates like Instructional Object-Based Game(IOBG). This enhances ethical practices that facilitate learning processes with the use of the teacher knowledge category as major principles of TPACK being specified in figure 1.

Technological pedagogical and content knowledge model (Mishra \& Koehler, 2009)

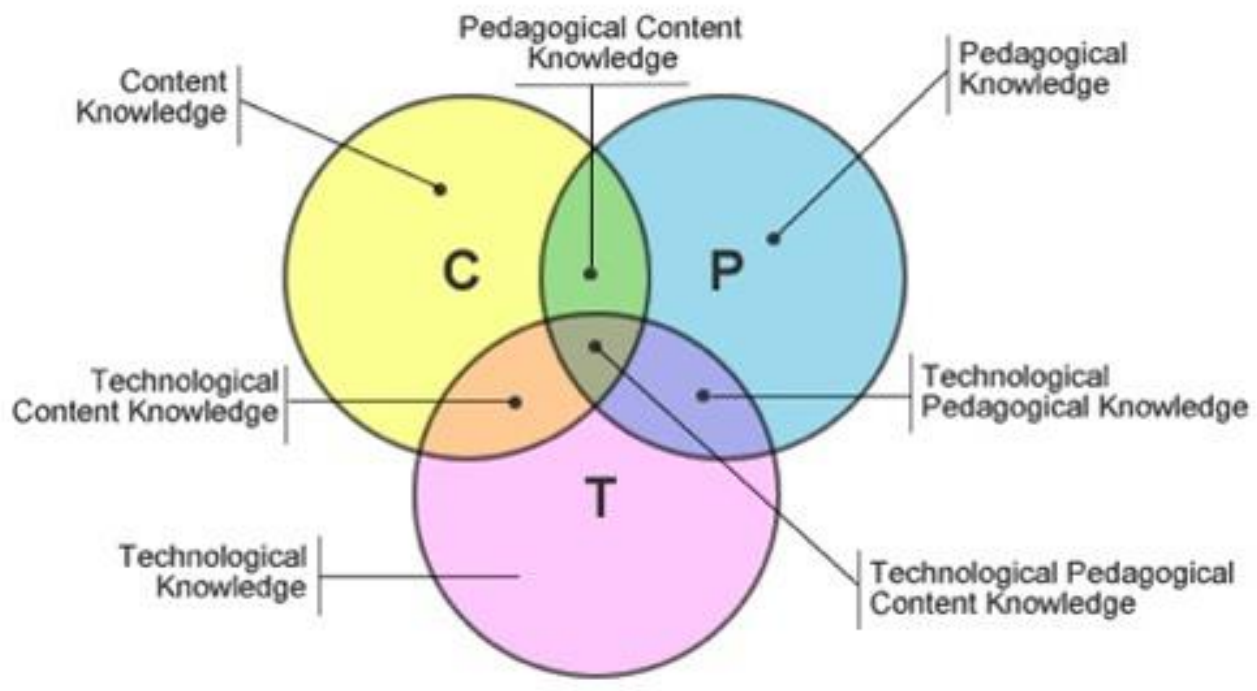

Figure 1: TPACK model

Source: Mishra \& Koehler (2009)

Table 1:Teachers' Professional Knowledge Base Categories (Shulman, 1987)

Definition

Category

Subject matter content Knowledge 
Academic related knowledge Subject matter knowledge includes information or data and the structures, rules, and conventions for organizing and using information or data.

Pedagogical Content Knowledge

The combination of content and pedagogy. Information or data that helps lead learners to an understanding would classify as pedagogical content knowledge. This includes any way of representing a subject that makes it comprehensible to others.

Curriculum Knowledge

Materials and programs that serve as "tools of the trade" for teachers. Knowledge of the curriculum can be considered vertical (within a discipline area across grades), or horizontal (within grade and across disciplines).

General Pedagogical Knowledge

Principles of classroom management and organization unrelated to subject matter. General pedagogical knowledge is unrelated to a specific subject matter and can therefore be implemented in a vast array of classroom settings.

Knowledge of Learners

Specific understanding of the learners' characteristics. These characteristics can be used to specialize and adjust instruction

Knowledge of Educational Contexts

An understanding of the classroom, the governance and financing of school districts, the character of school communities. Knowledge of the big picture surrounding the classroom helps to inform teachers about how the community may perceive their educational actions. This knowledge of educational contexts may also inform teachers about how to proceed in the classroom in relation to school, community, and state conventions, laws, and rules.

Knowledge of Educational Ends

The purposes and values of education as well as their philosophical and historical grounds. An understanding of the purposes and values of education will help teachers motivate learners.

Source: Shulman (1987)

\section{Object-Based Game Technology (OBGT) and Mathematics}

Due to the significant roles of content knowledge in teaching, it is needful to describe more concretely the functionality of OBGT. Process technologies and the processes involved in the use of adequate teaching technologies look-alike in action also develop assessments to measure and develop teaching strategies like IOBG. Scholars are beginning to consider technology within various content areas in Mathematics (e.g., AACTE Committee on Innovation and Technology, 2008).

Despite epistemological resistance from teachers with the use of technology in teaching Mathematics and slowly starting in the field of Mathematics education, there may be renewed interest in and even evolving viewpoints toward technology and Mathematics (Swan \& Hofer, 2008). Although the OBGT framework offers a theoretical explanation for teacher knowledge, challenges remain prevalent including the identification of ways to develop, assess, and measure OBGT. Research is now beginning to address these challenges. For example, Koehler, Mishra, and Yahya (2007) noted that over the course of the seminar, faculty moved from considering the technology constructs separately toward a more complex understanding of the nuanced interplay of technology construct. 
The continued interest in TPACK as an epistemological perspective in the preparation of inservice Mathematics and technology teachers and as a knowledge base for infusing game principles, content, and method in the study of technology has yielded a desperate need for Mathematics to produce a conceptual framework and taxonomy for the infusion of game upon which future TPACK studies in Mathematics and technology education can be based.

\section{Analog game, OBGT Model and TPACK}

The OBGT model (Figure 2) provides a framework for the development of analog in educational game development. The model integrated instructional factors proposed by Booker (2000 \& 2004) and key structural elements of games suggested by Prensky (2001) were examined. The game structure in this current study was designed in line with the instructional considerations such as conceptual analysis (content selection, performance procedure and problem-solving) was addressed in line with pedagogical content suggested by Shulman (1987). Instructional strategies (operationalisation of the instructional Mathematics card games, managing learning procedure and establishing the demonstration of knowledge), and students' strategies (level of learners') formed the technological outfits of the mathematical card game.

The Game Object Model (GOM) proposed by Amory (2007) was consulted. The GOM does not provide a framework that links learning theories to game design which OBGT model (Figure 2) does. It (OBGT) contains concrete interfaces to realize the educational objective represented by the abstract interfaces. The Game space embodies all the components (Visualization space, Elements space, and Problem space) serve as PCK. Game Achievement (GA) and interfaces (play, exploration, challenges and engagement) form TPACK suggested by Mishra and Kohler (2009).

The GA and OBGT articulate the process of designing and building educational games, in which the learning objectives are firstly defined to lead the activities, or actions of the game. This was suggested by Olatoye (2014) in accordance with TPACK principles. Each act needs to achieve specific objective(s).The objectives are implemented through the concrete interfaces of the Visualization space. Elements space (graphics, and technology), interaction, gestures and problem space (visual, logic, mathematical, short-term memory and manipulation) to express the abstract interfaces (critical thinking, discovery, goal formation, goal completion and practice). The suggested components were pulled together to serve as principles of TPACK and the contribution of this study to the body of knowledge. Also, the principles were adopted for the creation of Substitution Card Games (SCG) used for this study as template.
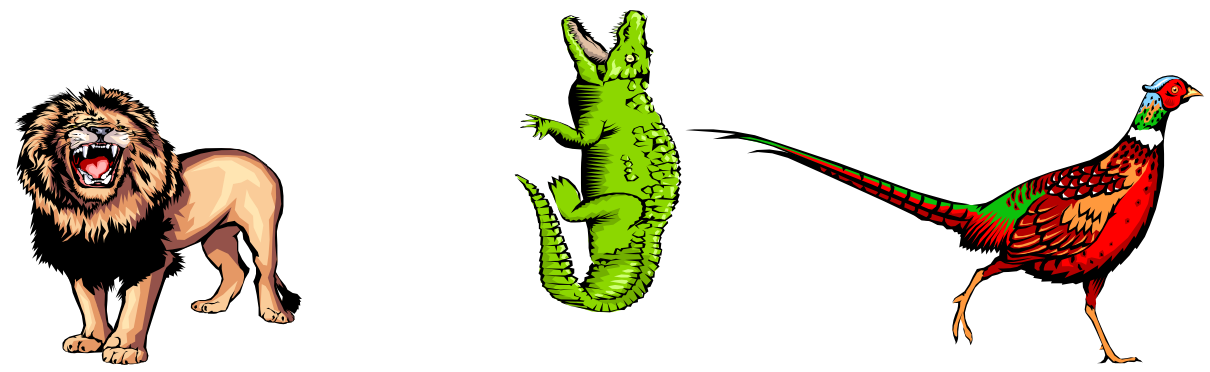

Figure2: Motivational/ Visualization interface 


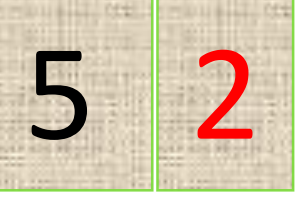

Operational process

$$
\text { Operational process } / *-+
$$

Figure 3: Abstract interface and Arithmetic operations

(i) $y=3 x+5$ or (ii) $y=8 x$ or (iii) $y=4 x-3$ (iv) $y=2 x+3$ (examples of Problem spaces: each of these appear on a card).

The Visualization space, concrete interface, elements space, problem space and abstract interface were pulled together to form each instructional card see detail in figure 3. Today's children need not only basic education, but also the ability to deal with an increasingly complex and connected world. There is a need to create inclusive educational solutions that address all sections of society and help transform them through motivation, provision of adequate teaching and learning facilities. The transformation must be a way to improve students' performance in school subjects particularly Mathematics. In doing this, educators have to create means that make learning an active construction of an individual's own knowledge by integrating new information with previous experience that enhanced recall such as instructional games (Garris, 2010).

For decades, studies have shown that game has been used to support students' learning and improve the academic performance of students' (Gee, 2009). Reflecting on the interests of the educators, studies have been conducted to explore the effects of games on students' achievement. Oblinger (2010) showed that computer games have received a lot of attention from educators as a potential way to provide learners with effective and fun learning environments. Gee (2009) agreed that a game would turn out to be good for learning when the game is built to incorporate learning principles. Some researchers have also supported the potential of games for affective domain learning and fostering a positive attitude towards learning (Ke, 2008; and Vogel et al., 2006).

Rosas et al., (2008) found a positive effect of educational games on the motivation of students. In the meta-analysis, Vogel et al. (2006) examined thirty-two (32) empirical studies and concluded that the inclusion of games for students learning resulted in significantly higher cognitive gains compared with traditional teaching methods without games. The specific interest of this study is to design Instructional Object Based Game (IOBG) Mathematics model, keeping with the current trajectories of TPACK research. Olatoye (2017) identified game technological pedagogical content knowledge as a necessary component for Mathematics teacher education programs to facilitate and increase integration of Game Technologies (GT) into Junior school Mathematics classes.

\section{Achievement and Games}

Andy Isaacs, the director of the third edition of Everyday Mathematics stated, "Not only do games engage students, but they also present the opportunity to ascertain "high level" Mathematics concepts in a colorful and simple way" (Isaacs as cited in Booker, 2004 p. 46). Since students participation levels are higher while playing games, retention of Mathematics 
concepts overtime is also higher (Betz, 1995). In order to present challenging Mathematics (math) concepts in "colorful" ways that lead to increase Mathematics achievement, it is essential to include math games throughout the curriculum. Using technology is a very efficient way to incorporate math games into curriculum. Corbeil (1999) examined the relationship that technology played on both the academic achievement, measured by standardized tests as well as the social environment of the school, encompassing student tardiness, teacher and student absenteeism and student and teacher morale. He found that the use of computer learning games that required students to use higher order thinking skills positively affected academic achievement. Computer learning games are one of many different teaching tools that can help increase student achievement in the classroom (Corbeil, 1999). When used for higher-order thinking skills, computer learning games help to increase student achievement, then it is vital to increase school funding for not only computer access in the classrooms; but professional development that will enable teachers to feel more confident effectively using technology.

\section{Learners' Performance}

Although there has been much reform in the way math is taught, many math curricula are still structured to teach students a plethora of isolated math concepts, often incorporating a "drill and kill" method of teaching. This does not encourage students to develop a strong conceptual foundation, making it very difficult for them to make relevant connections. It also does not teach students how to solve problem, reason mathematically and this may cause poor performance in Mathematics (Johnson \& Johnson, 2011; Corbeil, 1999).

Reflecting the interests of the educators, studies have been conducted to explore the effects of games on students' performance. However, there has been no consensus on the effects of computer games and instructional object-based games. Some studies support computer games as educational resources while others see instructional object-based games structured with pedagogical content as instructional resources to promote students' learning (Vogel et al., 2006).

Certain societal stereotypes can also inhibit a student's performance in mathematics. The idea that men are better at math than women, mathematics ability is inherited (Fillier, 2009). This study also sought to establish empirical evidence to support or den ace this body of knowledge.

\section{Ability and Game Parameter Estimate}

Ability in this context is a possibility or performance trait of an individual learner or user of the design card game, to be able to use the card among or between other learner(s) or users. Rasch assumes that the underlying trait being measured could be estimated as a function of the examinee ability and the item difficulty while item discrimination and the pseudo- guessing parameter are assumed constant. Items elicited from examinees have some forms of behaviour, (a) the examinee brings in some cognitive ability to overcome an item. (b) On the other hand, an item has some inherent cognitive resistance. The probability of an examinee overcoming an item is dependent of (a) and (b) (Nenty, 2007).

\section{Using IOBG in Teaching Mathematics Concepts}


Games have been explored as a pedagogical approach to enhance mathematical learning (Bragg, 2007). Mathematical games improve young children's number knowledge (Peters, 1998) and overcome tertiary mathematical difficulty (Gueron, 2001). Although teachers and parents agree that games help to improve children's knowledge (Fisher \& Neill, 2007), and students find learning through playing games a fun (Young-Loveridge, 2005), not much research has been done specifically on instructional games. Many teachers are doubtful on the use of games in learning Mathematics and the learning outcomes that could be obtained from games. One of the purposes of this current study was to develop an object-based card game, particularly for the topic substitution using liner equation, which focuses on the learning objectives of using arithmetic operation, directed numbers and fractions.

\section{Conflicts, Challenges, Competitive \& Obstacles in Solving Substitution}

Arise from the limited understanding of the mental picture of substitution and misinterpretations of the equation as two independent numbers. The challenge is maintained by presenting substitution that requires various strategies of ordering equations. The use of three separate interfaces makes the card game competitive. Obstacles like virtual enemies are created when using two separate arithmetic operations of different notation to resist the player in the game. These factors make the game hard but interesting.

\section{The Interaction}

The interaction of the players occurs, when a player substitutes for $\mathbf{x}$ in a chosen card and manipulates equation using arithmetic operation from his card. He relates the value of his own card with the opponent card or card met on the playing board to get result, when visualizes the representations of card value in the game, this creates interaction among the players. The social aspect of the game is possible when more than two players are allowed to play the game. The model in Figure 5 was in line with Lee (2007) who tested in a group of eight (8) years students using a manipulative tool of fraction cards in a pilot study. The findings of the study showed that students from different mathematical abilities have different views of the fraction games. Students' learning needs are incorporated into the model in order to develop instructional games that could fulfill different learning needs. Students could be given an option to choose the difficulty level based on their own abilities. The game provides teaching of substitution to students who failed to overcome the conflict of the game caused by their misconceptions and difficulties with linear equation.

\section{Difficulty Levels}

A range of difficulty levels is available in the card game for the player to choose from, including easy, normal and hard. The below-average students can play in increasing progress from easy to hard levels. The average student reviews equation at the easy level, apply their knowledge at the normal level and take the challenge at the hard level. The hard level maintains the interest of the above-average students while enabling them to learn more about linear equation.

\section{Pedagogical Approaches to the Instruction of Linear Equation}

\section{Visualization of Substitution}


The substitution used in the card game creates an opportunity for students to visualize the representations of symbols. The linear equations are structured with the use of varieties of symbols, numbers and arithmetic operations. As stressed in the concept of equal-whole number, fractions and equations can only be compared when the value of the card is obtained. Visualization of substituted value with the invariance of the whole number helps students to understand the order of equation value as quantity rather than a symbol. Limited knowledge of fractional parts is the obstacle that impedes students from carrying out meaningful computation with linear equation and fractional quantities (Young-Loveridge et al., 2007).

\section{Connection of Symbols and Representations of Equations}

Manipulation of substitution encourages the player to connect symbols and representations of equations. Playing with linear equations makes the player familiar with the substitution process. Furthermore, the player is making sense of number and symbols on visible linear equation before the value of card is obtained. When a fraction like equation appears, for example, $\mathrm{Y}=$ $3 \mathrm{X} / 2$ the player gains the ability to construct a representation of fraction and combination of two to three operations.

\section{Reasoning of Strategies}

Students are encouraged to learn more strategies for solving linear equations; these make them (students) gain the strongest and most durable knowledge of linear equations from learning to use different strategies. Normally, students think about substitution order in four basic ways (namely divided quantity, denominator and numerator, reference points and numerical conversion), but the thinking about divided quantity is fundamental to the reasoning of different substitution strategies. Hence, divided quantity shows a representation for each fraction question in the card game.

\section{Resolving Misconceptions}

Playing the substitution card game also helps students to resolve their misconceptions of linear equation. When the player makes an incorrect order of substitution, immediate and specific feedback is given and if an improper operation, is used, the player fails to play further or having negative results all through. Correcting each other's errors make them more aware of their own misconceptions. Similar questions are then posed to assist in retention.

\section{Game as Repertoire of Teaching Aids}

\section{Engaging}

The game can be used to engage students in the lesson of linear or quadratic equation. Visualisation of substitution as a topic helps students to gain a concrete understanding of fractions, indices and arithmetic operations, while manipulating linear or quadratic equation using substitution allows an active participation of learning. In addition, forming value for cards creates a meaningful problem context for substitutions. As such, the game provides a hands-on experience that makes the lesson more motivating and successful for students.

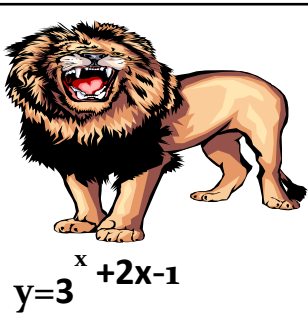


Figure 4: Visualisation of image and value representation.

(i) $1 / 3+2 / 5=5+6 / 15=11 / 15$

(iii) $1 / 3 \times 2 / 5=2 / 15$ (ii) $3^{-1} \times 3^{2}=3$

(iv) $1 / 3-2 / 5=5-6 / 15$

Equation: (i) represents addition of proper fractions, (ii) represents multiplication of indices and whole number, in solving this equation first law of indices will be applied i.e. $3^{-1+2}$. (iii) represents multiplication of two proper fractions. (iv) represents subtraction of two proper fractions. While equation $\left(y=3^{x}+2 x-1\right)$ is quadratic, $\mathbf{x}$ is to be substituted for in this type of equation.

\section{A Manipulative Tool}

Teachers can use the substitution card game as a manipulative tool to support children's partitioning of fractions, substitution, indices, arithmetic operations, and linear equations. Many children struggle to create a correct partition although some of them are able to imagine it. Dividing fraction, substituting value, and using all arithmetic operations requires the informal knowledge of equal-partitioning and the use of arithmetic operations, which is breaking a whole into parts (Streefland, 1993). Being seen as representations of many examples of divided quantities, the game can be used skillfully by teachers to reinforce children's developing knowledge of fractions, indices and arithmetic operations.

\section{Reflecting Mathematical Thinking}

Different ways of ordering linear equations by the students reflect their mathematical thinking. This allows teachers to learn more about students' strategies. Based on student thinking, the teacher can make the instruction more meaningful and engaging for students (Burrill, 1997). Teachers can also view their Mathematics teaching iteratively through the eyes of their students (Naiser et al., 2004).

\section{Analog Teaching}

The teaching of linear equations occurs when explaining various strategies of ordering in section of the game. Analog teaching is performed through dynamic visual images of substitution, fractions, indices, use of all arithmetic operations and numerical symbols. Teaching becomes effective when there is a need for learning from the player to win the game.

\section{Research Paradigm}

Research paradigms are philosophical learning theories revolved within the context of the study identifying individualist development and constrictive learning as a framework making game processes to be reflective and transformative. 
Gaming processes are tools for peer learning and serve as basic constrictive and individualist developmental approaches to domain of learning. Peer learning involves sharing of ideas, knowledge and experiences as opposed to independent learning. Peer learning by constructivist theory of learning is a means of active individual construction and a process of enculturation into classroom practice using gaming process. However, this study is in congruent with constructivist theory that using games as peer learning tools develop learners' ability to take control over their own learning. It also allows cooperation, communications, closeness, mutually and understanding of topic content due to intensity of the partnership. Peer learning to teaching and learning are informed by both constructivist and socio-cultural theories of learning. From both theoretical perspectives, the students are at the centre of all learning and teaching decisions. However, the different theoretical perspectives as well as perspective from different discipline and education policy documents mean that this concept is misinterpreted sometimes may be confusing for teachers. Most alternative terms used in the literature such as privilege socio-cultural theory for examples are: personalized learning, independent learning, autonomous learning, inquiry guided learning, team-based learning, problem based learning, peer instruction co-operative learning, collaborative learning (Black, 2007).

Peer learning approach (PLA) as identified with other learner-centred approaches stresses how learners developed basic drill and knowledge in Mathematics skill building using gaming activities. Process to transfer such learning to new contexts and application in an open-ended challenge such as: linear substitution, simple equation, inverse operation, quadratic substitution. A search result of teacher education research literature for PLA yields few studies to describe effective teacher practice in Mathematics from learning perspective, Cobb (1999) and Black (2007) argued that learning in this process should be viewed as both a process of active individual construction and a process of enculturation into the classroom practices.

\section{Traditional learning and Constructivist learning}

In a traditional teacher-centered classroom, the students are the listeners and followers. The teacher is the one given freedom to move about, to initiate actions and interactions, to ask questions and to set limits on activity times. The teacher is the one who gave the facts and defines the important ideas. The activity is generally the teacher's domain (Sandholtz, Ringstaff, \& Dwyer, 1997). The difference between the rise in student test scores and fall in student performance on complex tasks is explained by the new accountability factor for teachers and administrators (Sandholtz et al., 1997). Schools and teachers are limiting instruction to drill and practice which emphasizes the material that the national norms tests in order to meet the set level on standardized tests. In this situation, students became better test taker and but became worse at higher-order cognitive learners. This action of teaching to the test brought about reform efforts to move teaching instruction from rote learning to problem solving, concept development, and critical thinking. This new instruction philosophy is based on the constructivist theory of knowledge and learning.

Constructivism views learning as a personal, reflective, and transformative process where ideas, experiences, and points of view are processed into something new. In the knowledgeconstructed classroom, the students work together, sharing the process of learning not only with their peers but with parents and others (Sandholtz et al., 1997). 


\section{METHODOLOGY AND PROCEDURES}

Qualitative research was adopted which is referred to as "formative research" by Creswell (2003). Formative research methodology is a method of inquiry employed to understand phenomena, qualitative analysis from this research context is to elucidate and coordinate functional concepts and variables that revolve around the research work. Survey and classroom ecology types of qualitative analysis were adopted in the study and these involve the collection of texture and insightful ideas due to synergy building (Creswell \& Planoclark, 2007).Formative research was used to design and develop the process in contextual structure in the discovery of the underlying elements with the intention, leading the design of this study towards a naturalistic case of formative research.

Convenience and purposive sampling were used in selecting thirty (30) subjects from two Junior Secondary Schools II (J.S.S II) in Lagos Island. The selected subjects were mixed (the same number of male and female) and further paired into two for the card game play. The game play was carried out three times per week for one month during a long break. The performance of each player was recorded at the end of an every-each set of cards played.

Data collection and analysis techniques, observations, reports on peer performance, semistructured interviews with the subjects (participants) and content analysis were used. These data sources imply formative research.

\section{RESULTS AND DISCUSSION}

The findings were grouped based on processes related to the creation of card games, human relations among players and instructional design model process can be summarized as the following:

(a) Content selection in object-based game design involves what to teach, objectives the game intends to achieve and problem to be solved within subject matter drawn from Mathematics curriculum and it relates to: (see Figure 5)

- Level of learners: this involves determining users' level of ability (this involves introducing tasks/problem solving within the mental capacity of the learner), domains of learning (in game design, the designer has to set the rules of the game such that the activities of play affect all the domains of learning) and types of learner (this has to do with i.e. able, or physically challenge learner).

- Performance procedure and demonstration techniques: involve design of prototype, test run (pilot testing), and illustration or users' guide on the use of the game.

- Operationalization: this is playing procedure, rules of playing, determination of playing seeds (this include what to be used for playing such as cards or dice).

- Problem solving includes problem scenario, operational procedure and review of literature.

- Managing learning procedure: involves time management, task and class management.

\section{Content Selection}




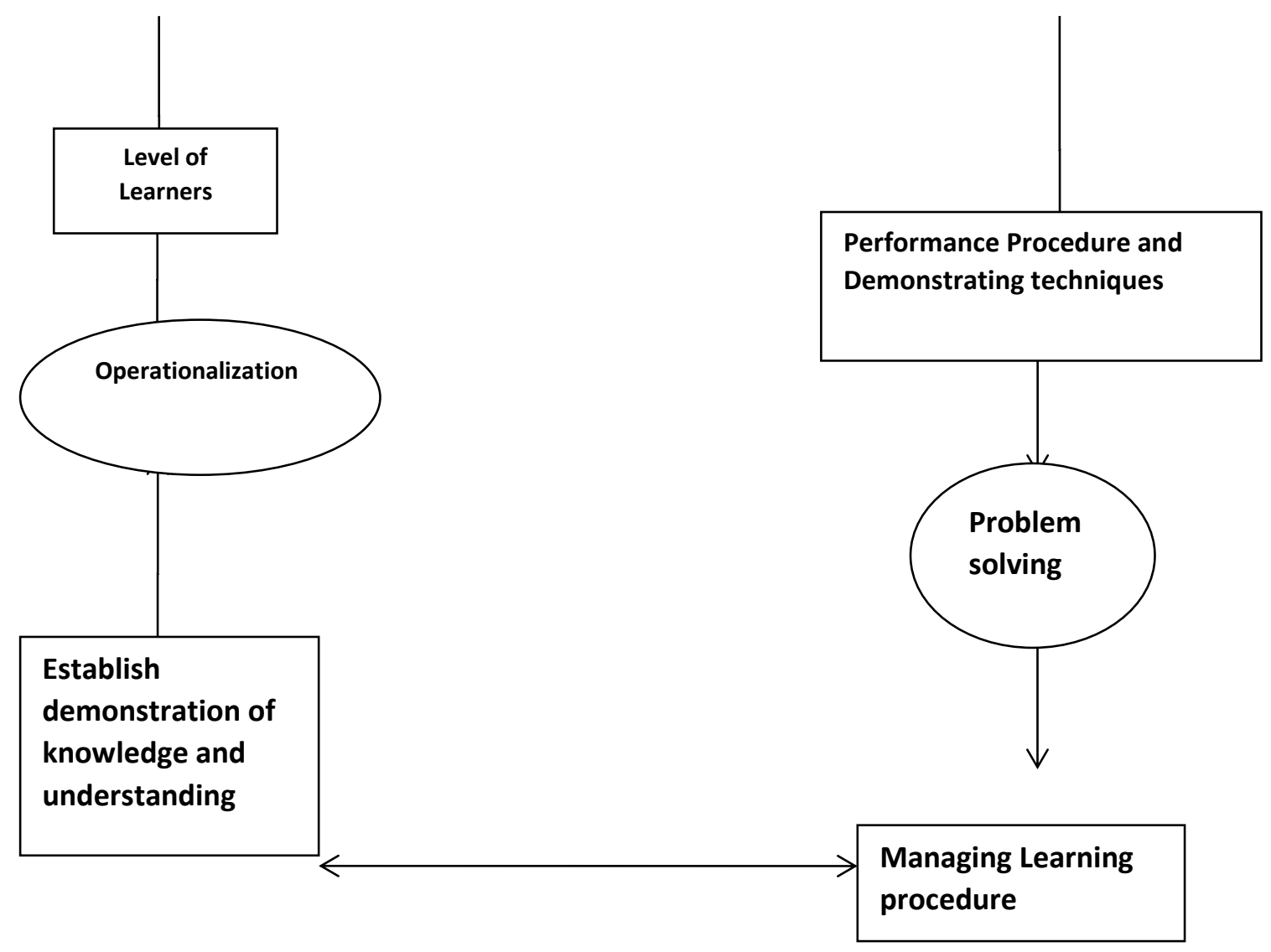

Figure 5. Managing learning procedure

\section{(b) Organization of Instructional Content}

Reiser, \& Dempsey (2012) and Mayer, (1992) identified developing content strategies to contextualized instructional material. Developing Content Strategies: allow contextualized entities provision such as collaboration, role play, case studies that permit multiple and varied perspectives. Contextualization helps learners to link new ideas to prior knowledge. Learners bring experience that is unique to their cultural and ethnic backgrounds. In addition, motivation and decision-making should be built in to the materials being developed. Develop the materials so that the instructor is not built into the process. This permits the greatest flexibility and encourages the development of materials that are focused on learner needs.

Mayer (1992) opines that some questions are pertinent while IOBG or other related instructional materials are being designed, these include:

1. What is an instructional design strategy? This includes learner analysis, identification of goals \& objectives, sequencing of events, delivery modes (i.e., self-paced, instructorled, etc.) and assessment tools.

2. Do I have enough funds available? This would include not only the cost of developing or adapting existing materials, but the cost of maintaining the instructional materials over time.

3. What resources do I have to put in place? Keep in mind both your resources and ability to create the IOBG as well as the resources and ability of the instructor and learner to use these instructional card games. Is the technology accessible, flexible, or 
difficult to learn? Duffy \& Cunningham (1996) were of the view that some skills were required when developing the content for IOBG. This is required to assess the skills that are likely to be developed by using the instructional materials that were created or selected. The material should be designed to develop these skills, depending upon the goals and objectives. These skills include:

- person-to-person communication

- giving and receiving feedback

- leadership

- teamwork and cooperation

- conflict resolution

- Instructional Design (also called Instructional Systems Design (ISD)) is the practice of creating instructional experiences which make the acquisition of knowledge and skill more efficient, effective, and appealing.

- The goal of this learning experience is to develop the skills needed to design instructional material. The content is organized according to the ADDIE model of Analysis, Design, Development, Implementation, and Evaluation.

- The sequence of activities for instructional design may also be described as identifying instructional needs, identifying instructional goals, designing instruction and assessment, implementing and assessing the design, and then revising goals, design, and implementation as necessary:

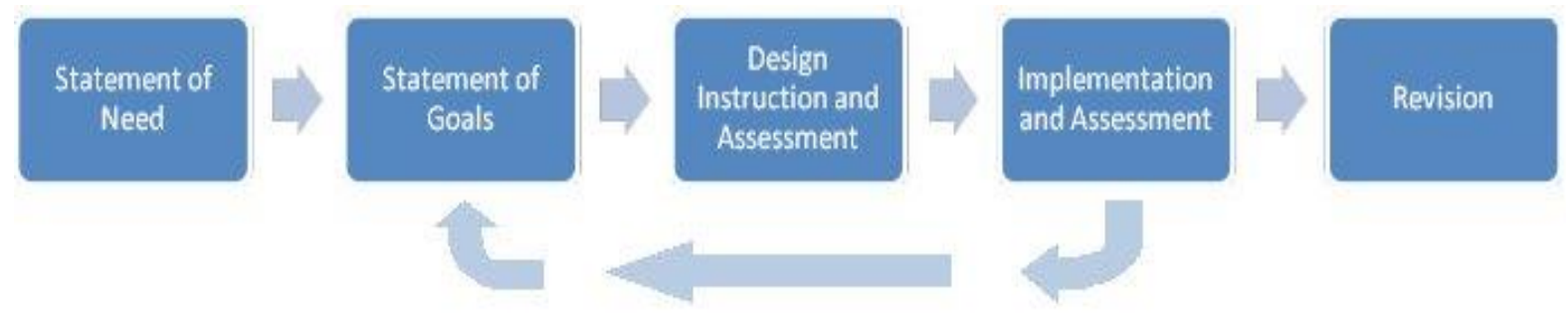

\section{Figure 6: ADDIE model}

\section{c. this relate to Instructional Object Based Mathematics Card Games Design Format}

This section consists of game design format that is methods of design, scheming and how each card operates among other cards to facilitate players strive toward the attainment of a goal within prescribed rules. The section was structured in line with the purposes of the study which include, the design of an instructional object-based game using TPACK principles, as well as an educational game that contains clear, specific goals and rules that should enhance performance and learning outcomes. The study also investigated the use of an Instructional Object Based Game (IOBG) using a formative research process in teaching selected topics in Mathematics.

The effective and efficient use of estimation, measurement and calculation among other concepts has formed the idea of basic mathematics in our daily life. Algebraic substitution was coined from Mathematics whose tentacles spread to linear substitution, and simple equation, inverse operation, quadratic substitution these are applicable to the junior secondary curriculum and its application spread to the world of work and all walks of life situation. This formed the strength of this package to solve algebraic substitution problems and each card was designed using TPACK principles. 
The objectives of this card game (package) are to aid children in acquiring new concepts; also, to assist children in developing and extending their Mathematics concepts. The game however, provides drudgery out of the practice of skills and indeed of making the practice more effective. The steps involved in developing the card game followed the Instructional Object-Based Game Technology design model in Figure 5 in this research study.

Topic: This product is basically designed to solve algebraic substitution problems.

Target Population: This card is constructed to meet the level of students in Junior Secondary II with the age range 10-15 years.

Entry Behaviour: Pupils ought to have learnt the following:

Laws of Indies

Fraction

Application of Arithmetic Operations

\section{Arithmetic Operations}

(*) Represent Multiplication

(/ or $\div$ ) Represent Division

(+) Represent Addition

(-) Represent Subtraction

\section{Prototype of IOBG Design using TPACK principles}

1

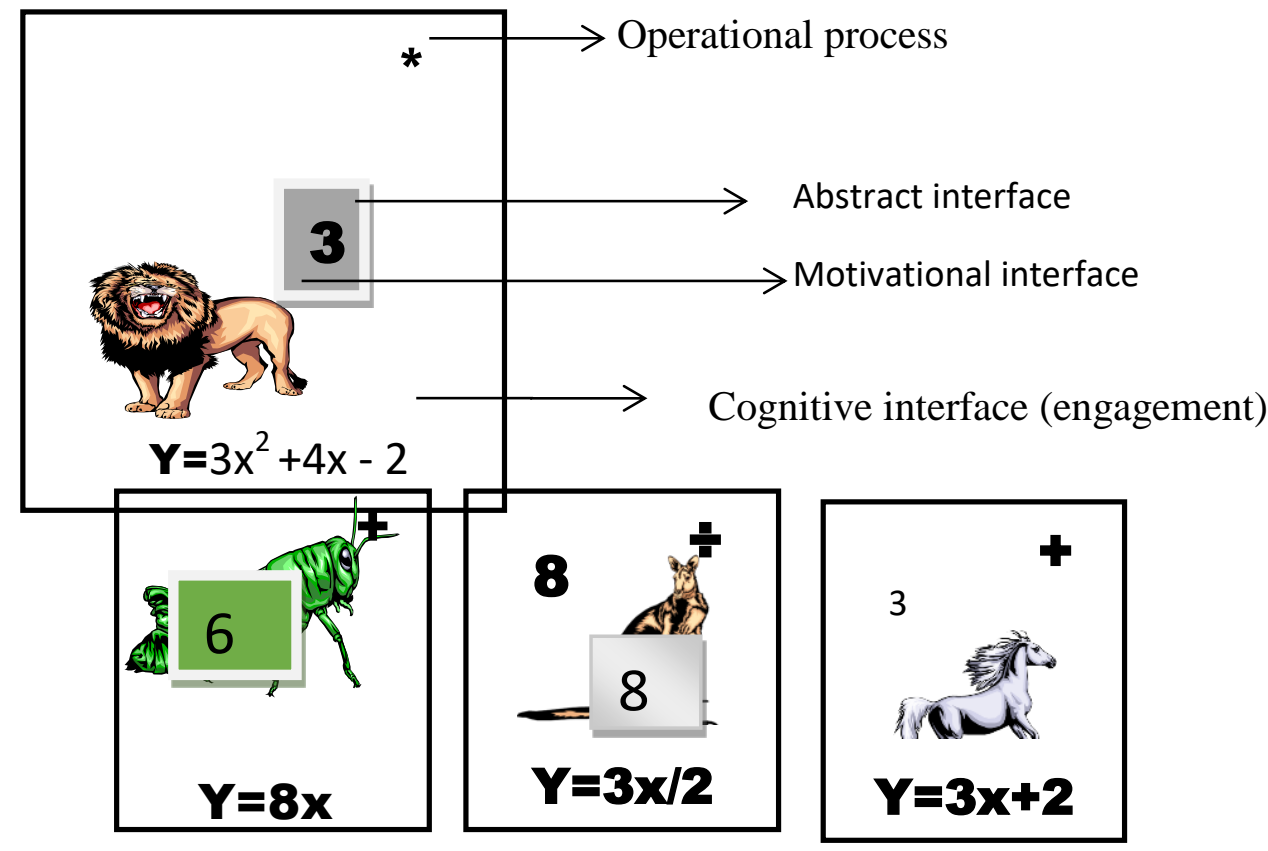

Figure 7: Card Game Design samples

\section{(i) The rules}


- The first player plays on the assumed card value of the playing card.

- Operation is based on face value of the last played card for subsequent play.

- The use of calculator is allowed in computing only the final result.

\section{(ii) The Goal}

The goal is to substitute the number in the middle of the card for $\mathrm{X}$ in the equation at the bottom of the card surface, to be able to have the value of the card and also use arithmetic operation at the top-right edge of the card to relate with other cards on the playing board. If the substitution is formed correctly. Y gives the value of the card and the player uses this value and arithmetic operation in his card to play the card on board then he has his score. The player can move on to another card. Examples: The middle number that appears on each card represents $\mathrm{X}$, which is substituted for in the equation at the bottom of the card.

To determine the value of the card, see Figure 7 above. The first card has the value of $\mathrm{Y}=8$ (6) $=48$, while the second card has the value of $Y=3 * 8 / 2=12$.

The arithmetic operation at the right top edge of the corner of each card is used as the operating factor between two cards.

\section{How to Play the Game}

The number of the players shall be two and above. The players shall combine the three functions on the card to determine the scores of the player(s).

(i) First playing card

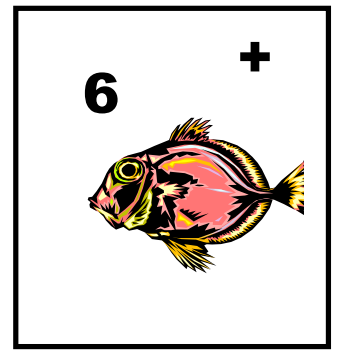

(ii) Second playing card

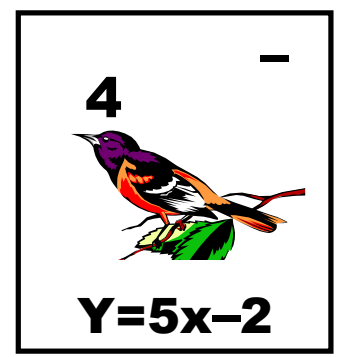

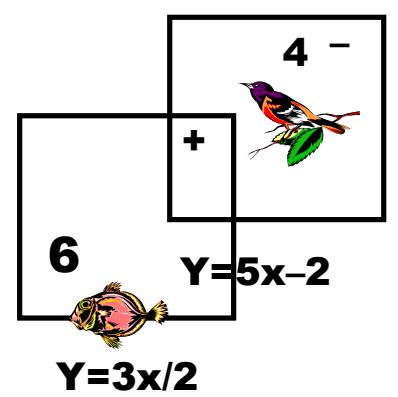

\section{$\mathbf{Y}=3 \mathbf{x} / 2$}

Figure 8: How to play the card game pattern

$\mathrm{X}$ equals to the bold

number on the card.

The number is substituted

in place of $\mathrm{x}$ in equation

at the bottom of the card
The second playing card

has the value of the card to

be $Y=5(4)-2=18$ but

met +9 on board therefore

the score will be $9+18=27$ 
to give score of 9 i.e.

$\mathrm{Y}=\underline{3 \times 6}=9$

2

(iii) Third playing card

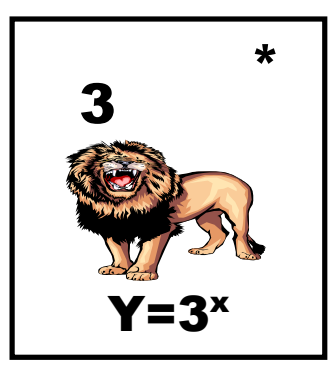

Figure 9: Third Playing Card

The 3rd playing card has the value of 27 but meets 18 on board. Using-operation on the second playing card, one plays 18 and 27 i.e. $18-27=-9$

\section{(iv) Fourth Playing Card}

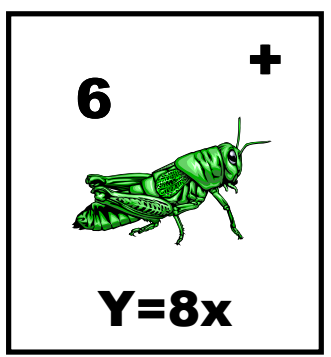

The 4th playing card has the value of his card to be 48 and meets 0 (zero) on board. Therefore, this score will be $48 * 27=1296$

Figure 10:Fourth Playing Card

\section{How Cards Operate among each other}

Table 2 examines how a card interacts with another card, the interrelations were based on a matrix, and the matrix was designed on probability bases. 
Table 2: Operationalization of the cards

\begin{tabular}{|l|l|l|l|l|l|l|l|l|l|l|l|l|l|l|l|l|}
\hline$*$ & $\mathrm{a}^{0}$ & 2 & 3 & 4 & 5 & 6 & 7 & 8 & 9 & 10 & 11 & 12 & 13 & 14 & 15 & $*$ \\
\hline $\mathrm{a}^{0+}$ & & & & & & & & & & & & & & & & $\mathrm{a}^{0} \div$ \\
\hline 2 & & & & & & & & & & & & & & & 2 \\
\hline 3 & & & $4^{*} 3^{\div}$ \\
\hline
\end{tabular}

Figure11.Card operationalization

Using combination process the matrix forms $4 * 3^{\div}, 4 * 3^{+}, 4 * 4,3 \div 4 * 3 \div 4$, these are possible combinations.
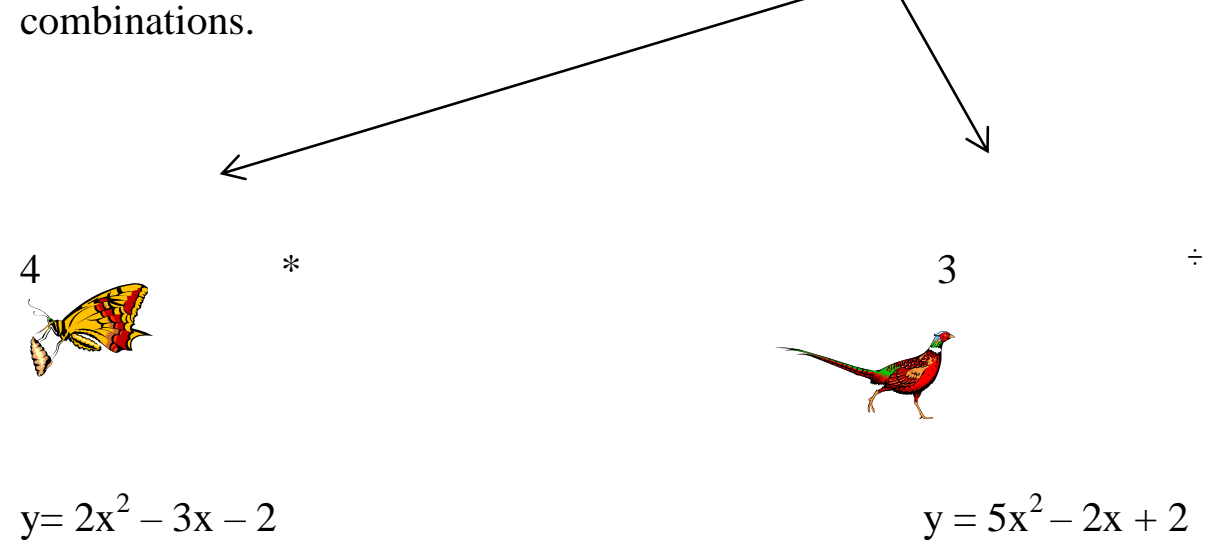
From game template in column four (4) row one, the card value is $y=2 x^{2}-3 x-2$, Substituting the first 4 into the equation the value will be $y=2(4)^{2}-3(4)-2$ the answer is 18 . The second number 3 indicates $y=5 x^{2}-2 x+2$ substituting 3 for $x$, therefore the value of the card is 41 . with the previous empirical evidence. This was done in view to concretize additional empirical evidence on the use of Mathematical object- based card games.

\section{CONCLUSION AND SUGGESTION}

The outcomes allow visualization and comparison of scores, this motivates the players to proceed on the next play card until the whole cards are extorted. Positive feedback and rewards are given, such as attractive winning scores. If an improper operation is formed, the player fails to play further or having negative results all through. The quality of game developed depends on the qualifications; i.e. proficiency in mathematical theories and their interrelations to suit instructional concepts of game development and creative thinking abilities, pedagogical skills are required to identify learning pattern. There is need to create the game operationalization and interaction among each other. Before embarking on Instructional mathematics object game, there is a need to assess the users, the topic and the content to cover from mathematics curriculum, the level of users', conduct learners' analysis this involve in real observations, surveys, structured and semi-structured interview with the target group. The actual target group's background information such as skills, attributes, characteristics, prior knowledge, and required entry competencies before embarking on playing the game.

\section{CONFLICT OF INTEREST}

There are no conflicts of interest with this paper.

\section{FUNDING}

No funding received to complete this research.

\section{REFERENCES}

AACTE Committee on Innovation and Technology (Ed.). (2008). Handbook of technological pedagogical content knowledge (TPCK) for educators. New York: Routledge.

Amory, A. (2007). Game object model version II: A theoretical framework for educational game development. Educational Technology, Research and Development, 55(1), 51-77. https://doi.org/10.1007s11423-006-9001-x

Amory, A., Naicker, K., Vincent, J., \& Adams, C. (1999). The use of computer games as an educational tool: 1, identification of appropriate game type and game element. British Journal of educational Technology Systems, 24, 195-205. https://doi.org/10.1111/1467$\underline{8535.00121}$

Asim, A. E. (2007). Examination ethics and school based assessments in science, technology and mathematics: A critical concern for universal basic education. Proceedings of the $9^{\text {th }}$ National Conference of National Association of Evaluators and Researchers. AgoIwoye, Ogun state. 
Asim, A. E., Kalu, I. M., Idaka, I. E., \& Bassey, S. W. (2009). Competency in STM assessment: The case of primary school teachers in cross River state, Nigeria. Proceedings of international Conference to Review Research in science, Technology and Mathematics Education (episteme-2), Feb. 12- 15, Mumbai, India.

Behr, M. J., Wachsmuth, I., Post, T. R., \&Lesh, R. (1984). Order and equivalence of rational numbers: A clinical teaching experiment. Journal for Research in Mathematics Education, 15, 323-341. https://doi.org/10.2307/748423

Bell, R. C. (2008). Person fit and person reliability. http://www.rarsh.org/erp8.htm. (Retrieved on June $28^{\text {th }}, 2012$ ).

Betz, J. A. (1995). Computer games: Increases learning in an interactive multidisciplinary environment. Journal of Educational Technology systems, 24, 195-205. https://doi.org/10.2190/119M-BRMU-J8HC-XM6F

Blanchard, J. S. \&Cheska, A. (1985). The Anthropology Of Sport: An Introduction. Massachusetts: Bergin and Garvey Publisher Inc.

Booker, G. (2004). Playing to win: using games for motivation and the development of Mathematical thinking. In A Rogerson (Ed.). The mathematics education into the $21 \mathrm{st}$ century project: Proceedings of the international conference: The future of mathematics education. Pod Tezniami, Ciechocinek, Poland.

Booker, G. (2000). The Maths Game: Using Instructional Games To Teach Mathematics. Wellington: NZCER.

Bragg, L. (2007). Students' conflicting attitudes towards games as a vehicle for learning mathematics: A methodological dilemma. Mathematics Education Research Journal, 19(1), 29-44. https://doi.org/10.1007/BF03217448

Burrill, G. (1997). Choices and challenges. Teaching Children Mathematics, 4, 58-63.

Chandra, V. \&Lioyd, M. (2008). The methodological nettle: ICT and Student Achievement. British Journal of Educational Technology, $39 \quad$ (6) 1089-1098. https://doi.org/10.1111/j.1467-8535.2007.00790.x

Christou, C., Jones, K., Mousoulides, N. and Pittalis, M. (2006). Developing the 3DMath Dynamic Geometry Software: theoretical perspectives on design. International Journal for Technology in Mathematics Education, 13(4), 168-174.

Corbeil, P. (1999). Learning from the children; practical and Theoretical Reflections on playing and learning simulation and Gaming. Simulation \& Gaming, 30 (2), 163-180. https://doi.org/10.1177/104687819903000206

Cox, S. (2008). A conceptual analysis of technological pedagogical content knowledge. [Unpublished Doctoral Dissertation], Brigham Young University.

Creswell, J. W. (2003). Research design: Qualitative, quantitative, and mixed methods approaches $\left(2^{\text {nd }}\right.$ ed.). SAGE.

Doering, A., Veletsianos, G., \&Scharber, C. (2009). Geomantic: Designing and assessing with technological, pedagogy, and content knowledge. Contemporary issues in technology and teacher education. (on line serial), 9(3). http://www.citejournal.org/vol9/iss3/socialstudies/article.cfm. (Retrieved February $13^{\text {th }}$, 2012).

Fisher, J., \& Neill, A. (2007). Exploratory study of home-school partnership: Numeracy. In Findings from the New Zealand Numeracy Development Project 2006. Wellington: Ministry of Education. 
Frierich, F. (1957). Learning Through Play. The Mathematics Laboratory Ausgewah The Scriften. 4, (2), 20-24.

Garris, R. (2010). Games, Motivation, and Learning: a research and Practice model. Simulation and Gaming, 33, (4) 441-467. https://doi.org/10.1177/1046878102238607

Geddis, A. N. (1993). Transforming Content Knowledge: Learning to Teach about Isotopes. Science Education, 77, 575 -591. https://doi.org/10.1002/sce.3730770603

Gueron, S. (2001). A game-like activity for learning Cantor's theorem. The College Mathematics Journal, 32, 122-125. https://doi.org/10.2307/2687118

Hughes, J. E. (2000). Teaching English with Technology: Exploring Teacher Learning and practice. [Unpublished Doctoral Dissertation], Michgan State University.

Johnson, D. W. \& Johnson, R. T. (2011). Learning Mathematics And Cooperative Learning, Lesson Plans For Teachers, Minnesota: Interactive Book Company.

Ke, F. (2008). A Case Study of Computer Gaming for Math: Engaged Learning from Game Play? Computer and Education, $51 \quad$ (4), 1609-1620. https://doi.org/10.1016/j.compedu.2008.03.003

Ke, F., \& Grabowski, B. (2007). Game playing for math's learning: Cooperative or not? British Journal of Educational Technology, 38 (2), 249-259. https://doi.org/10.1111/j.1467$\underline{\text { 8535.2006.00593.X }}$

Koehler, M. J., \& Mishra, P. (2010). Introducing TPCK, AACTE committee on Innovation and Technology (Ed.).The handbook of technological pedagogical content knowledge for educators. 3-29.

Koehler, M.J., Mishra, P., \& Yahya, K. (2007). Tracing the development of teacher knowledge in a design seminar: Integrating content, pedagogy, and technology. Computers and Education, 49 (3), 740-762. https://doi.org/10.1016/j.compedu.2005.11.012

Mayer, R.E. (2003). The promise of multimedia learning using the same instructional design methods across different media, Learn. Instruc. 13: 125-139. https://doi.org/10.1016/S0959-4752(02)00016-6

Naiser, E. A., Wright, W. E., \&Capraro, R. M. (2004). Teaching fractions: Strategies used or teaching fractions to middle grade students. Journal of Research in Childhood Education, 18 (3), 193-198. https://doi.org/10.1080/02568540409595034

Nenty, H. J. (2007). Item response theory: Quality- enhancing measurement technique in education. African Journal of Educational Studies, 5, 1. https://doi.org/10.7202/1025005ar

Ni, Y. \& Zhou, Y. (2005). Teaching and learning fraction and rational numbers: The origins and implications of whole number bias. Educational Psychologist, 40 (1), 27-52. https://doi.org/10.1207/s15326985ep4001_3

Niess, M. L. (2005). Preparing Teachers to Teach Science and Mathematics with technology: Developing a technology pedagogical content knowledge. Teaching and Teacher Education. 21, 509-523. https://doi.org/10.1016/j.tate.2005.03.006

Oblinger, D. G. (2010). Games and Learning. EDUCASE Quarterly, 29 (3), $5-7$.

Olatoye, M.. A. (2017). Structured Instructional process and performance of Junior Secondary School 2 Students in Mathematics. Journal Pendidikan Malaysia. 42(2),135-145. https://doi.org/10.17576/JPEN-2017-42.02-07 
Peters, S. (1998). Playing games and learning mathematics: The results of two intervention studies. International Journal of Early Years Education, 6 (1), 49-58. https://doi.org/10.1080/0966976980060105

Randel, J., Morris, B., Wetzel, C. \& Whitehill, B. (1992). The effectiveness of games for educational purposes: A review of recent research. Simulation \& Gaming, 23, 261-276. https://doi.org/10.1177/1046878192233001

Randhawa, B. S., Beamer, J. E., \& Lundberg, I. (1993). Role of the mathematics self-efficacy in the structural model of mathematics achievement. Journal of Educational Psychology, 85, 41-48. https://doi.org/10.1037/0022-0663.85.1.41

Reimer, K., \& Moyer, P. S. (2005). Third-graders learn about fractions using virtual manipulatives: A classroom study. The Journal of Computers in Mathematics and Science Teaching, 24 (1), 5-25.

Sandholtz, J., Ringstaff, C., \& Dwyer, D. (1997). Teaching With Technology: Creating StudentCentered Classroom. Teachers College Press.

Shulman, L. S. (1986). Those who understand: Knowledge growth in teaching. Educational Researcher, 15 (2), 4-14. https://doi.org/10.3102/0013189X015002004

Shulman, L. S. (1987). Knowledge and teaching: Foundations of the new reform. Harvard Educational Review, 57 (1), 1-22. https://doi.org/10.17763/haer.57.1.j463w79r56455411

Singh, K. Granville, M., \&Dika, S. (2002). Mathematics and science achievement effects of motivation, interest, and academic engagement. Journal of Educational Research, 95 (6), 323-332. https://doi.org/10.1080/00220670209596607

Thompson, A., \& Mishra, P. (2008). Breaking news: TPCK becomes TPACKS! Journal of Computing in Teacher Education, 24 (2),38-64.

Vogel, J.J., Vogel, D. S., Cannon-Bowers, J., Bowers, C. A., Muse, K., \& Wright, M. (2006). Computer gaming and interactive simulations for learning: A meta-analysis. Journal of Educational computing Research, 34(3), 229 - 243. https://doi.org/10.2190/FLHVK4WA-WPVQ-H0YM

Watson, A. \& Sullivan, P. (2008). Teachers Learning About Tasks and Lesson. In D. Tirosha\& Woods (Eds.). International Hand Book Of Mathematics Teachers Education: Tools Processes In Mathematics Teacher Education. 2, 109-134 Rotterdam, Sense Publication. 